\title{
Sistema carcerário feminino: uma análise das políticas públicas de segurança com base em um estudo local
}

\author{
BRUNA RIOS MARTINS SANTOS ${ }^{1}$ \\ VÂNIA APARECIDA REZENDE ${ }^{2}$ \\ ${ }^{1}$ UNIVERSIDAde Federal de SÃo JoÃo del-REI (UFSJ), SÃo JoÃo DEL- REI - MG, BRASIL \\ ${ }^{2}$ UnIVERSIDAde Federal de SÃo JoÃo DEL-REI (UFSJ) / DEPARTAMENTO dE CIÊNCIAS ADMINISTRATIVAS E CONTÁbEIS, SÃO JOÃO DEL-REI - MG, BRASIL
}

\begin{abstract}
Resumo
Embora a taxa de encarceramento feminino tenha aumentado significativamente nos últimos anos, a construção de políticas públicas que englobam a perspectiva de gênero ainda é um processo estatal a ser consolidado na agenda governamental. Este trabalho apresenta o estudo de um caso que teve como locus de investigação o universo carcerário feminino de uma comarca no estado de Minas Gerais, seu objetivo foi analisar como a diferença de gênero, na construção de políticas públicas de segurança no sistema prisional, influencia as vivências do feminino no cárcere. A pesquisa, de natureza qualitativa, utilizou entrevistas com roteiros semiestruturados e análise documental. Os dados produzidos foram submetidos à análise de conteúdo proposta por Bardin, cuja categorização textual ocorreu pela classificação de elementos constitutivos de um conjunto e reagrupamento com base em características comuns destes elementos. Por meio desta análise, foram construídas quatro categorias: encarceramento e gênero; maternidade e cárcere; políticas públicas e vivências no cárcere. Os principais resultados apontam que as especificidades de gênero no encarceramento feminino influenciam as vivências produzidas resultantes de vários tipos de violência que marcam definitivamente a vida das mulheres, destacando-se a relação com a maternidade, apontada como a principal fonte de sofrimento. Apesar de avanços significativos, a inserção da questão de gênero na formulação das políticas públicas de segurança pública ainda é recente e incipiente no que tange às especificidades do cárcere feminino.
\end{abstract}

Palavras-chave: Políticas Públicas. Segurança Pública. Cárcere Feminino. Gênero.

\section{Female prison system: a case study of public security policies}

\begin{abstract}
Although the rate of female incarceration has increased significantly in recent years, building public policies that encompass the gender perspective is still a state process to be consolidated in the government agenda. This article presents a case study that investigates the female prisoner universe of a region in the state of Minas Gerais. The objective was to analyze how gender differences influence the construction of public security policies in the prison system, and affects the experiences of female prisoners. This qualitative research used semi-structured interviews and documentary analysis, the data produced were submitted to content analysis proposed by Bardin, whose textual categorization occurred by classifying constituent elements of a set and regrouping from the common characteristics of these elements. From this analysis, four categories were constructed: imprisonment and gender; maternity and prison; public policies; and prison life. The main results indicate that gender differences in the elaboration of policies related to the prison system influence the experiences of incarcerated women, particularly regarding motherhood. Although significant advances were made to adequate public policies to the specificities of female prisoners, this is still a recent and incipient issue.
\end{abstract}

Keywords: Public policy. Public security. Female prision. Gender.

\section{Sistema carcelario femenino: un análisis de las políticas públicas de seguridad a partir de un estudio local}

\section{Resumen}

Aunque la tasa de encarcelamiento femenino haya aumentado significativamente en los últimos años, la construcción de políticas públicas que engloban la perspectiva de género sigue siendo un proceso estatal a consolidarse en la agenda gubernamental. Este trabajo presenta el estudio de un caso que tuvo como locus de investigación el universo carcelario femenino de una comarca del estado de Minas Gerais, su objetivo fue analizar cómo la diferencia de género, en la construcción de políticas públicas de seguridad en el sistema penitenciario, influye en las vivencias de lo femenino en la cárcel. La investigación, de naturaleza cualitativa, utilizó entrevistas con guiones semiestructurados y análisis documental. Los datos producidos se sometieron al análisis de contenido propuesto por Bardin, y su categorización textual se llevó a cabo por la clasificación de elementos constitutivos de un conjunto y reagrupamiento a partir de las características comunes de estos elementos. Por medio de este análisis se construyeron cuatro categorías: encarcelamiento y género; maternidad y cárcel; políticas públicas y vivencias en la cárcel. Los principales resultados apuntan que las especificidades de género en el encarcelamiento femenino influencian las vivencias producidas resultantes de varios tipos de violencia que marcan definitivamente la vida de las mujeres, especialmente, la relación con la maternidad, indicada como la principal fuente de sufrimiento. A pesar de los avances significativos, la inserción de la cuestión de género en la formulación de políticas públicas de seguridad pública todavía es reciente e incipiente en lo que se refiere a las especificidades de la cárcel femenina.

Palabras clave: Políticas públicas. Seguridad pública. Cárcel feminina. Género. 


\section{INTRODUÇÃO}

O encarceramento feminino no Brasil aumentou significativamente nos últimos anos, fato que repercute tanto nas políticas públicas de segurança quanto nas políticas específicas que visam combater a desigualdade de gênero. Apesar de as mulheres serem minoria no mundo da criminalidade, a taxa de encarceramento feminino subiu vertiginosamente no país. A população absoluta de mulheres encarceradas cresceu 656\% entre os anos de 2000 e 2016, chegando ao patamar de 42.355 mulheres presas, ao passo que a população de homens encarcerados cresceu $293 \%$ no mesmo período. Em relação à taxa de aprisionamento de mulheres por 100 mil habitantes, o Brasil ocupa o terceiro lugar, atrás somente dos Estados Unidos e da Tailândia (BRASIL, 2017a; FBSP, 2018).

O crescimento desta população encarcerada suscita a necessidade do debate acerca da questão de gênero. Sua inserção na agenda governamental brasileira deu-se em resposta à atuação dos movimentos feministas e sob influência de organismos internacionais (FARAH, DINIZ, MARCONDES et al., 2018). No entanto, o atendimento disponibilizado na prisão às mulheres encarceradas é praticamente o mesmo destinado aos homens, não contemplando suas particularidades - há um tratamento indiferente que torna o processo de ressocialização de mulheres apenadas ainda mais complexo (FRANÇA, 2014).

É estratégico abordar a questão de gênero como tentativa de impulsionar a criação de políticas públicas que considerem a situação do encarceramento feminino. No entanto, trata-se de um campo cujo dissenso é a característica central que orienta a tentativa de definição conceitual e o modus operandi expresso em projetos específicos de políticas públicas (FONSECA, 2016). A necessidade de um ponto de inflexão em pensar as ações estatais destaca-se com a realidade dos presídios femininos e a penalização das mulheres encarceradas; além da privação de liberdade, enfrentam precárias condições carcerárias. Configura-se espaço que não foi construído com base nas especificidades de gênero, cujas normas penais e sua execução foram estruturadas do ponto de vista masculino, desconsiderando as especificidades femininas (BORGES, 2005; ARTUR, 2009).

A (des)construção do conceito de gênero perpassa pelo fato histórico de seu desenvolvimento fruto do movimento feminista; por outra ótica pode-se afirmar sobre a percepção de um conceito socialmente construído. Em meio a esta (re)construção social e cultural, atribuem-se capacidades específicas e espaços contemplando prioridades a cada sexo. A difusão do termo demonstra uma polifonia e riqueza embutida nessa arena de debates, constituindo-se terreno definitivo e consolidado de construção epistemológica (MATOS, 2008; MUXÍ, 2014; MOTTA, 2017).

As políticas de segurança pública apresentam uma natureza interdisciplinar, fato que leva sua institucionalização a uma diversidade de frente de ações. Nesse sentido, o constructo "vivências", explorado neste trabalho, encontra eco nas interfaces com várias áreas de conhecimento. Segundo Uziel e Scisleski (2018), o sistema prisional e a segurança pública passaram a contar com incursões psicológicas e assim contrapor a lógica punitivista. Desse modo, os autores se inquietam em relação a quais práticas no sistema prisional investem na produção de formas de fazer morrer as existências invivíveis/invisíveis. De forma complementar, considera-se também a colaboração da sociologia contemporânea na análise de políticas, que, segundo Cortes e Lima (2012), observa as identidades sociais bem como a dos atores relacionados aos estudos acerca da constituição de grupos sociais que podem demandar ou ser objeto de políticas públicas. Por vivências, este estudo apoia-se no conceito de que o que foi vivenciado em uma intensidade de tal modo significativa transforma por completo o contexto geral da existência de um indivíduo. Assim, a vivência deve ser relevante o bastante para conferir importância decisiva na vida daquele que a vivencia, sendo impossível determinar racionalmente seu conteúdo (VIESENTEINER, 2013).

O propósito deste trabalho alinha-se a Farah, Diniz, Marcondes et al. (2018) quando relembram que o início da reestruturação das políticas públicas de gênero aconteceu com a incorporação da questão de gênero pela agenda governamental brasileira, fato que se deu em resposta à atuação dos movimentos feministas e sob influência de organismos internacionais. Em outro estudo, Farah (2004) identificou que o campo de estudos de gênero consolidou-se no Brasil no final dos anos 1970, concomitantemente ao fortalecimento do movimento feminista no país. Depreende-se daí a reflexão de que as ideias aqui apresentadas encontram eco em um campo amplamente abrangente. Este estudo, ao tratar de uma materialização empírica local, revela-se como uma oportunidade de ampliar o debate relacional entre gênero e políticas públicas.

Partindo dessa contextualização, este artigo tem por objetivo analisar em que medida a diferença de gênero na construção de políticas públicas de segurança no sistema prisional, em um nível local, influencia as vivências do feminino no cárcere. Este trabalho teve como locus de investigação o universo carcerário feminino em uma comarca no estado de Minas Gerais. Este artigo, além desta introdução, buscou contextualizar as políticas públicas no cenário brasileiro bem como o recorte de gênero. Em sequência, especificou-se o percurso metodológico, foram apresentadas as análises dos resultados e as considerações finais. 


\section{Políticas Públicas de Segurança e o Contexto Brasileiro}

A Política Pública enquanto área de conhecimento e disciplina acadêmica nasceu nos Estados Unidos como uma subárea das Ciências Políticas e teve seus estudos regidos pelo pressuposto de que, em democracias estáveis, aquilo que o governo realiza pode ser cientificamente formulado e analisado por pesquisadores. Perante a complexidade e a falta de consenso sobre o conceito, em uma visão geral, a elaboração das políticas públicas está relacionada à necessidade de solucionar situações para promover o bem comum da sociedade. Criticamente argumenta-se que estas definições ignoram o embate em torno de ideias e interesses que seriam a essência da política. No entanto, a política pública instrumentalizada pode assumir diferentes valores em seus parâmetros de acordo com o nível de presença do Estado na provisão dos bens e serviços (SOUZA, 2003; BREUS, 2006; SARAVIA, 2006; SOUZA, 2006; LIMA, 2011).

O Estado brasileiro passou por uma série de reformas nas últimas décadas. Sob a influência das transformações no cenário internacional nas décadas de 1950 e 1960, pode-se constatar que novas formas de gerenciamento e de planejamento foram implementadas no Brasil. A partir da década de 1970 e 1980 emergiu um novo cenário em direção à redemocratização que culminou com a instauração da Assembleia Nacional Constituinte e a promulgação de uma nova Constituição em 1988. Esta Carta ampliou os direitos sociais, garantindo-os por meio de políticas públicas.

No âmbito das políticas de Segurança Pública, estas podem ser compreendidas pela função de preservar ou restabelecer a convivência social e permitem, conforme cita Silva (2009, p. 635) "[...] que todos gozem de seus direitos e exerçam suas atividades sem perturbação de outrem, salvo nos limites de gozo e reivindicação de seus próprios direitos e defesa de seus legítimos interesses". Para Filocre (2009), a política de segurança pública torna-se uma política pública se nela existir uma proposta, a um só tempo, de forma de organização da vida social e de ações visando a certo objetivo de interesse público. No contexto brasileiro, Adorno (2002) postula que, desde meados da década de 1970, exacerbou-se o sentimento de medo e insegurança no Brasil perante as estatísticas oficiais de criminalidade que indicaram a aceleração do crescimento de todas as modalidades delituosas.

A promulgação da Constituição de 1988 ampliou a perspectiva democrática com introdução de novas abordagens acerca de temas como direitos sociais, garantias fundamentais e respeito à dignidade humana. A Constituição estabelece, em seu artigo 144, que: "[...] a segurança pública, dever do Estado, direito e responsabilidade de todos, é exercida para a preservação da ordem pública e da incolumidade das pessoas e do patrimônio" (BRASIL,1988). A nova Carta definiu as regras do jogo político e os limites da legalidade, abrindo possibilidades para a organização dos atores em demandar ação dos governos (BREUS, 2006; LIMA, 2011).

O processo de redemocratização brasileiro e as pressões sociais determinaram uma modificação nos modelos de políticas públicas na área de segurança, ampliou-se o debate sobre necessidade de reformas estruturais. Na visão de Carvalho e Silva (2011), apesar de a Constituição de 1988 estabelecer um compromisso com a segurança individual e coletiva, medidas inconsistentes e paliativas a situações emergenciais deslocadas da realidade social foram propostas. Este período incorporou novos atores no ciclo das políticas públicas, começaram a se multiplicar no Brasil movimentos, organizações não governamentais e centros de pesquisa com o objetivo de desenvolver práticas e estratégias para o controle da violência pública e favorecer a incorporação destas medidas nas políticas públicas de segurança (ZACCHI, 2002). A segurança pública necessita ser compreendida como um processo articulado no qual há uma interdependência institucional e social.

As iniciativas na área de segurança pública sofreram modificações nas últimas décadas com a introdução de novos paradigmas que podem ser pensados por três eixos: "[...] o paradigma da segurança nacional, vigente no regime militar; o paradigma da segurança pública, que entra em voga a partir da Constituição de 1988 e o paradigma da segurança cidadã, que se inicia por volta dos anos 2000" (FREIRE, 2009). O Atlas da Violência (IPEA e FBSP, 2018) aborda a ideia de governança em segurança pública denotando uma responsabilidade difusa de vários atores e instituições. Defende-se uma pluralidade de interesses em disputa que precisam ser administrados, ressaltando a defesa constitucional de que segurança é uma responsabilidade de todos.

A área de segurança requer o estímulo de uma articulação intergovernamental e intersetorial por meio de programas específicos voltados para a descentralização e embasados em ações preventivas que utilizam a participação social. As práticas para a redução da violência e da criminalidade podem ser concentradas em três eixos: por meio da aproximação com a população; do uso intensivo de informações; e do aperfeiçoamento da investigação e da inteligência (SOUZA, MARCHIORI, OLIVEIRA et al., 2009; SCHABBACH, 2014; LIMA, BUENO e MINGARDI, 2016). No entanto, conforme demonstra o Anuário do Fórum Brasileiro de Segurança Pública, de 2018, houve um crescimento de 2,9\% de mortes violentas intencionais entre os anos de 
2016 e 2017. Em interface com o sistema carcerário, o Anuário afirma que 729.551 pessoas estavam encarceradas em 2016; ressaltando-se que o sistema penal conta com 368.049 vagas, ou seja, há duas pessoas presas para cada vaga (FBSP, 2018).

Na tentativa de intervir nos pontos críticos identificados na segurança pública, algumas medidas foram adotadas nas últimas décadas. Com a Carta de 1988, formou-se o Conselho Nacional de Segurança Pública (CONASP), que atualmente funciona como um modelo tripartite, composto por representantes da sociedade civil, membros governamentais e trabalhadores da área de segurança pública. $\mathrm{O}$ órgão buscou a cooperação técnica entre os entes federativos no combate à criminalidade, até então subordinado diretamente ao Ministério da Justiça, que foi desmembrado depois da criação do Ministério da Segurança Pública em fevereiro de 2018, pela Medida provisória no 821. A medida está alinhada à ideia de funcionamento do Sistema Único de Segurança Pública, o SUSP, também já aprovado no Congresso.

Anteriormente destacaram-se outros marcos, como a criação da Secretaria Nacional de Segurança Pública (SENASP) em 1997, a construção, em 2000, do I Plano Nacional de Segurança Pública e do Fundo Nacional de Segurança Pública (FNSP), e a criação do Programa Nacional de Segurança Pública com Cidadania (PRONASCI) em 2007 (BRASIL, 2000; SCHABBACH, 2014). Já em 2017, com o intuito de combater altos índices de violência, foi lançado um novo Plano Nacional de Segurança Pública, tendo como principais objetivos: reduzir homicídios dolosos, feminicídios e a violência contra a mulher; realizar um combate integrado à criminalidade organizada transnacional e racionalizar e modernizar o sistema penitenciário (BRASIL, 2017b).

Outra ação relevante foi a instituição da Política Nacional de Trabalho no Âmbito do Sistema Prisional (PNAT), por meio do Decreto no 9.450/2018, voltada à ampliação e qualificação da oferta de vagas de trabalho, ao empreendedorismo e à formação profissional das pessoas presas e egressas do sistema prisional (BRASIL, 2018). O Estado brasileiro mostra indícios que pressupõem a sedimentação da ideia de unificação de esforços em torno da segurança pública, os delineamentos de cooperação entre os entes federativos parecem preconizar um movimento que pode potencializar as diretrizes para a formulação das políticas públicas desta área, o financiamento da política de segurança foi de 84,7 bilhões em 2017, sendo distribuídos entre os níveis de governo federal, estadual e municipal; o gasto com cada cidadão foi de $R \$ 408,13$, correspondendo à $1,3 \%$ do PIB (FBSP, 2018).

O Atlas da Violência 2018 (IPEA e FBSP, 2018), ao apresentar os crescentes números sobre a violência no Brasil, demonstra a premência de ações compromissadas e efetivas por parte das autoridades nos três níveis de governo, prevê que a agenda da segurança pública deve envolver ações intersetoriais e integradas que incluam, além dos executivos, o Parlamento, a Justiça, o Ministério Público, a Defensoria e também a academia, as igrejas, os empresários e toda a sociedade civil organizada. Segundo o Conselho Nacional de Justiça, somente em 2017 ingressaram no Poder Judiciário 2,7 milhões de novos casos criminais (CNJ, 2018).

\section{Recortes de Gênero nas Políticas Públicas}

A inclusão da questão de gênero nas políticas públicas brasileiras ainda é considerada um tema recente, adquirindo visibilidade apenas a partir da década de 1980 no contexto de redemocratização e movimentos sociais. Dessa maneira, caminhar para as políticas integradas de gênero ainda é uma aspiração distante, embora tenham ocorrido avanços. As reivindicações neste contexto posicionam o Estado como principal vetor de mudanças via políticas públicas (FARAH, 2004; SILVEIRA, 2004; SORJ, 2008; VASONE e SANTANA, 2015; FARAH, DINIZ, MARCONDES et al., 2018).

Na década de 1980, Beauvoir (1980) condensa a dimensão dos estudos de gênero, ao conjecturar que os indivíduos nascem machos e fêmeas e se tornam homens e mulheres, uma vez que tal fato não é um destino assumido na sociedade e, sim, escolhas promovidas dentro da civilização. Bourdieu (2012, p. 17) ressalta que "[...] a divisão entre os sexos parece estar 'na ordem das coisas". Para o autor, ela está presente, ao mesmo tempo, em estado objetivado nas coisas (na casa, por exemplo, cujas partes são todas "sexuadas"), em todo o mundo social e, em estado incorporado, nos corpos e nos habitus dos agentes, funcionando como sistemas de esquemas de percepção, de pensamento e de ação.

O conceito de gênero e suas categorias de análise enfatizam as relações sociais entre os sexos e as desigualdades de poder estas tendem a ressaltar a condição de subordinação da mulher na sociedade. Referem-se à construção social da identidade sexual, estabelecendo uma correlação entre comportamentos e personalidades em oposição à divisão sexual biológica (SOARES, 2004; SCAVONE, 2012; MUXÍ, 2014; MOTTA, 2017). A incorporação deste debate na agenda pública 
deu-se no final dos anos 1970. Com a mobilização de mulheres que buscavam a superação das desigualdades, iniciou-se esta discussão (FARAH, 2004).

Para que as políticas públicas inserissem a questão de gênero, foi necessária uma longa trajetória de movimentos feministas, construídos no decorrer da história brasileira. Silveira (2004) ressalta a importância da participação social das mulheres em espaços de definição política, disputa por recursos e mecanismos de controle social dessas políticas, bem como a possibilidade de acesso aos espaços de decisão. Corroborando este posicionamento, Nascimento (2016) afirma que a eficácia das políticas públicas de gênero depende da compreensão das demandas femininas e da participação ativa das mulheres no seu processo de elaboração.

Desde a criação da Secretaria Nacional de Políticas para Mulheres, em 2003, têm ocorrido avanços na construção de políticas públicas pautadas na transversalidade de gênero. Um dos instrumentos de viabilização foi o Plano Nacional de Políticas para Mulheres (PNPM), elaborado a partir de 2004. Destacando este marco, Farah, Diniz, Marcondes et al. (2018) afirmam que as políticas públicas com recorte de gênero obtiveram maior centralidade após a criação desse órgão e ganharam espaço na agenda governamental. Nesse cenário, o PNPM propôs um processo complexo de participação social e atuações intersetoriais visando reduzir as desigualdades de gênero. Destacou-se que, para a transformação dos espaços de opressão e da invisibilidade das mulheres dentro do aparato estatal, faz-se necessário adotar uma política pública pautada na transversalidade e uma ressignificação de conceitos (BRASIL, 2013).

A discriminação de gênero acentua-se na classe de mulheres encarceradas. A situação agrava-se na medida em que quase nenhuma política pública é desenvolvida, o que torna a mulher encarcerada invisível, levando-a vivenciar novas experiências que vão modificar substancialmente o modo como lidam com determinados aspectos de suas vidas (VIESENTEINER, 2013; CHESKYS, 2014).

\section{PERCURSO METODOLÓGICO}

A pesquisa, de cunho qualitativo, trata-se do estudo de um caso em uma comarca do estado de Minas Gerais, com abrangência em oito municípios. Em virtude do teor da temática, optou-se por ocultar a localização. Os ambientes definidos para a pesquisa foram o Presídio Regional administrado pelo poder estadual, por meio da Secretaria de Estado da Defesa Social, e a Associação de Proteção e Assistência ao Condenado (APAC). O presídio conta com uma população carcerária de 682 acautelados, com 4 mulheres e 678 homens. Por sua vez, a APAC pode abrigar 80 recuperandas; no momento da pesquisa abrigava 67 mulheres destas, 28 presas estavam em regime provisório, fato justificado por não haver outro local que pudesse receber as presas deste regime.

A coleta de dados ocorreu por meio de dois roteiros de entrevistas distintos, um direcionado às autoridades ligadas ao sistema prisional feminino e outro voltado às encarceradas. O roteiro direcionado aos gestores foi composto por 11 questionamentos elaborados visando compreender as diferenças de gênero por eles percebidas na dinâmica da execução das penas, as políticas para combater a desigualdade de gênero e a maternidade. Já o roteiro voltado para as apenadas, composto por 14 perguntas, contemplou o perfil das apenadas pelos seguintes aspectos: idade, profissão e tempo de encarceramento. Além desses aspectos, 04 questões referentes à percepção destas sobre a influência do gênero, 02 sobre a compreensão a respeito de políticas públicas, 02 ligadas diretamente à maternidade e 04 sobre suas vivências no cárcere. Visando complementar os dados, usou-se também pesquisa documental.

A coleta de dados ocorreu entre dezembro de 2017 e maio de 2018. Após apresentação e explicação da proposta aos entrevistados, disponibilizou-se o Termo de Consentimento Livre e Esclarecido, no qual todos concordaram espontaneamente em participar. O material foi gravado e transcrito, gerando um total de 29 páginas, em média uma página e meia por entrevistado, constituindo o corpus de análise. Cada entrevista durou cerca de 30 a 40 minutos, a depender da fala dos entrevistados. Não se obteve êxito em conseguir autorização para realizar as entrevistas no presídio, dessa maneira o estudo ficou centralizado na APAC, totalizando 19 entrevistas, distribuídas entre 02 gestores e 17 recuperandas.

A análise de conteúdo foi entendida como o método mais adequado para o alcance dos objetivos, uma vez que permite descobrir as questões implícitas dos conteúdos manifestos, indo além das aparências do que está sendo comunicado (MINAYO, 2009). Enquanto método, utiliza procedimentos sistemáticos e objetivos de descrição do conteúdo das mensagens produzindo 
conhecimento válido por meio da descoberta de conteúdos e estruturas. Desta perspectiva, as diferentes fases da análise de conteúdo organizam-se em torno de três etapas cronológicas: a pré-análise, a exploração do material e o tratamento dos resultados. Assim os dados são tratados de maneira a serem significativos e válidos, gerando inferências e interpretações a propósito dos objetivos previstos (BARDIN, 2009; BARDIN, 2016).

As informações foram organizadas e estruturadas textualmente tendo por base as premissas teóricas determinadas pela análise de conteúdo. Com apoio em Bardin (2016) e Minayo (2009), as informações coletadas, após várias leituras, foram classificadas em um sistema de categorias definidas seguindo as fases de pré-análise, exploração, tratamento e interpretação. A categorização consistiu em classificar os elementos constitutivos de um conjunto por diferenciação e, em seguida, reagrupá-los por analogia. O critério ocorreu pela categorização textual, onde os elementos constitutivos de um conjunto foram reagrupados por características comuns entre eles (BARDIN, 2016). Com base nesta análise, foram construídas quatro categorias: encarceramento e gênero; maternidade e cárcere; políticas públicas e vivências no cárcere.

\section{RESULTADOS COM BASE NAS CATEGORIAS IDENTIFICADAS}

Foi traçado o perfil sociodemográfico das mulheres encarceradas. Dentre as 17 entrevistadas, todas são nascidas nos munícipios amparados pela comarca. As recuperandas entrevistadas têm, em média, 34 anos; $75 \%$ possuem filhos, em média 3 filhos e em sua maioria adolescentes. Constatou-se ainda que, antes da prisão, 06 das entrevistadas se declararam donas de casa, 0 restante trabalhava, predominantemente, em atividades informais como artesãs e acompanhantes de idosos. Por sua vez, os dois gestores entrevistados possuem perfis diferentes, um é membro do poder judiciário (referente ao presídio) e o segundo (referente à gestão da APAC) tem um histórico na vida política nos poderes legislativo estadual e municipal.

A pesquisa demonstrou que, apesar de abrigar detentas (04 mulheres), o presídio regional não possui nenhuma área que tenha sido construída para as mulheres levando em conta suas especificidades e particularidades. Dessa forma, aquelas que se encontram nesse local convivem com uma realidade provisória e improvisada, cujos relatos identificam um espaço impróprio, permeado por diversos tipos de violência. Esta constatação foi possível pelo relato de 08 entrevistadas do sistema APAC sobre suas passagens pelo presídio.

Em relação à estrutura física, a APAC estudada foi uma das primeiras a serem criadas em Minas Gerais. Segundo o Tribunal de Justiça do Estado de Minas Gerais (TJMG), existem 11 APACs femininas no país, sua metodologia visa à humanização do cumprimento da pena privativa de liberdade (MINAS GERAIS, 2018). A ideia de humanização foi apresentada por meio de fatores relatados nas entrevistas, quais sejam: as recuperandas não usam uniforme, são responsáveis pelo preparo das refeições, praticam atividades religiosas, atividades físicas, têm acesso a livros, possuem espaço destinado à amamentação e têm direito à visita íntima. Ainda como parte desta metodologia, contam com um médico clínico geral e capacitação profissional desenvolvida por meio de atividades artesanais (crochê, bordado), de limpeza e cozinha. Segundo os gestores entrevistados, estas ações visam auxiliar no processo de reabilitação e ressocialização.

\section{Categoria 1: encarceramento e gênero}

A primeira categoria foi a interface entre o encarceramento e as questões relativas ao gênero. Embora tenham ocorrido alguns avanços na legislação e no sistema prisional feminino, a mulher encarcerada permanece em uma situação de invisibilidade representada pela ausência de respeito às suas necessidades físicas, sociais e psicológicas. Esta categoria ressalta a desigualdade de gênero no contexto penitenciário, como já abordado por Santa Rita (2006), ao ressaltar que a prisão reflete a discriminação e a seletividade do sistema penal. Os relatos abaixo retratam a categoria em análise:

Pra mulher, é pior. O preconceito com a mulher é maior. A sociedade não aceita uma mãe de família ser presa. Pra eles, a gente não presta (E9).

Lá na masculina, eles têm mais privilégio... têm mais regalia. Eles recebem kit de higiene. A gente não recebe shampoo, absorvente, sabonete. A família que tem que comprar (E12).

Segundo os gestores entrevistados, todas as mulheres condenadas na comarca em estudo cumprem as penas na APAC feminina. O Presídio Regional fica destinado apenas àquelas que "infringem as regras disciplinares", como medida punitiva determinada 
pela Vara de Execução Penal. Um deles afirma "a APAC é o purgatório, já o Presídio é o inferno". Este posicionamento é constatado por uma entrevistada:

Aqui na APAC, a gente tem dignidade, respeito. Lá no presídio, quando a gente ia pedir uma coisa pro diretor, ele virava pra gente e falava assim: "não enche, vai embora, que eu quero tomar minha cerveja". Falavam que a gente tinha que apanhar porque tava muito abusada. Era spray de pimenta todo dia. A alimentação lá era horrível, eu cheguei aqui igual uma caveira. Não comia nada, a comida era horrorosa, tinha um cheiro horrível. No Natal, serviram comida azeda pra gente. Não quero voltar pra lá de jeito nenhum (E3).

Outra relação com a interface de gênero foi a constatação de que 12 das 17 entrevistadas possuem pelo menos um familiar ou companheiro do sexo masculino que também se encontra preso, um índice de 70,58\%. Tal fato converge com os resultados obtidos por Posada (2015), que, ao estudar uma população carcerária, constatou que a maioria também tinha pelo menos um parente com experiência de encarceramento. A maioria está presa em virtude de acusação de tráfico de drogas. Um dos gestores entrevistados alega que o fato de estas mulheres conviverem em um ambiente no qual o crime - principalmente o tráfico de drogas - é realizado por seus filhos, irmãos e maridos torna aquela prática se torne habitual.

Discutir a categoria gênero demonstra a invisibilização da mulher encarcerada e a falta de políticas públicas que considerem a realidade das unidades prisionais femininas, assim como identificado por Rampin (2011). Para Andrade (2011), o papel associado à prisão tem sido o de devolver à sociedade boas mães e esposas, capazes de cumprir seu papel social.

\section{Categoria 2: maternidade e cárcere}

Segundo um levantamento do Conselho Nacional de Justiça (CNJ), por meio do Cadastro Nacional de Presas Grávidas e Lactantes, o Brasil possui 622 mulheres presas que estão grávidas ou são lactantes - deste total, 373 estão grávidas e 249 amamentam seu filho. Estes dados foram contabilizados até o último dia de 2017. No estado de São Paulo está custodiada a maioria destas mulheres, Minas Gerais vem em segundo lugar (CNJ, 2018).

A principal dificuldade apresentada pelas mulheres encarceradas foi a condição da mulher como mãe - das 17, apenas 4 não possuíam filhos. Todas concordaram que a maternidade agrava o enfrentamento feminino do cárcere. No momento da pesquisa, não havia nenhuma presa gestante ou lactante, entretanto, duas entrevistadas engravidaram e tiveram seus filhos enquanto cumpriam pena na APAC. Ambas relataram a sensação de humilhação e solidão por terem passado por essa experiência. O sofrimento causado com a relação maternidade e cárcere evidenciou que a condição de mulher e mãe agrava ainda mais o enfrentamento feminino da privação da liberdade - esta categoria também foi apontada por Guedes (2006). As falas seguintes retratam este quadro agônico:

O homem é mais forte, a gente é mais sensível, a mãe sofre pelos filhos. Eu sinto até mal na hora que eu tô fazendo comida e lembro dele (do filho), de alguma coisa que ele gosta (E1).

É mais difícil pra mulher por causa dos filhos. Ver eles chorando é muito triste (E2).

Com a alteração promovida no Código de Processo Penal, pela Lei no 13.257, de 2016, ficou prevista uma substituição da prisão preventiva pela domiciliar em casos de gestantes ou mulheres com filhos de até 12 anos de idade (BRASIL, 2016). 0 surgimento dessa possibilidade de pena alternativa poderia ter um reflexo direto nesta categoria, entretanto, a aplicação da lei ainda não está sendo vivenciada na prática entre a maioria das mulheres. Na visão de um dos gestores, essa alteração na lei muda a história do encarceramento feminino, porém "[...] dá um cheque em branco para as mulheres cometerem crimes, pois sabem que não ficarão presas se engravidarem e ainda é um direito do filho não ter uma mãe criminosa" (G2).

Retrata-se aqui o tratamento da maternidade como exclusivamente condicionante à liberdade, desconsiderando suas várias dimensões. Contrariamente, pela visão das recuperandas, a motivação de mudar e não cometer mais crimes decorre, justamente, do fato de terem filhos, reforçando que o vínculo familiar auxilia no processo de ressocialização da mulher encarcerada. Posada (2015) verificou que os filhos adolescentes com mães encarceradas têm um risco 10,8 vezes maior de entrar em conflito com a lei do que adolescentes com pais encarcerados. $\mathrm{O}$ afastamento enfraquece o vínculo entre mães e filhos e compromete a relação com o cuidado destes. 


\section{Categoria 3: políticas públicas}

O eixo estruturador desta categoria se forma com a discussão teórica sobre políticas públicas objetivando garantir ações que prevejam a ressocialização. Para isso, são necessárias atuações que abranjam o sistema prisional feminino e suas peculiaridades. Esta foi uma categoria essencial identificada na pesquisa. Este campo defende a ideia de que as políticas públicas são moldadas em todas as suas fases por diferentes tipos de atores e instituições e que seus diversos atores podem estabelecer relações (ALMEIDA e GOMES, 2018).

Ainda com apoio em Almeida e Gomes (2018), ao pensar no processo de políticas públicas como algo constituído por atores, instituições, redes/subsistemas, ideias/crenças, fatores contextuais e eventos, pode-se afirmar que, na comarca analisada, mesmo que de forma incipiente alguns programas são implementados, mesmo que de forma incipiente, visando à ressocialização e reintegração à sociedade. No entanto, as instâncias diversas de se pensar em políticas públicas, no âmbito da pesquisa, são prioritariamente voltadas ao universo masculino.

Foram identificadas algumas ações efetivas. Há na APAC, por exemplo, um espaço onde são ministradas aulas, sendo possível a realização do Exame Nacional do Ensino Médio para pessoas privadas de liberdade e jovens sob medida socioeducativa, 0 Enem PPL. A pesquisa constatou que, por meio desse processo, na APAC masculina, seis detentos foram aprovados em uma universidade federal, enquanto nenhuma mulher obteve este resultado. Desta mesma ótica, identificou que o projeto "Remição pela Leitura", recomendado pelo Conselho Nacional de Justiça é realizado somente no carcerário masculino. Especificamente para o carcerário feminino, a prefeitura disponibiliza vagas para varrição de rua. Tal situação gerou reclamações em todas as entrevistas com as encarceradas, que perceberam esse cenário como um privilégio para os homens.

Perante esse sentimento e percepção de exclusão na agenda governamental, as entrevistadas compartilham a ideia de que o processo de ressocialização depende mais da vontade delas do que de ações estatais. Um avanço específico, no estado de Minas Gerais, foi a aprovação da Lei Estadual no 22.864, de 2018, que determinou a destinação de $20 \%$ dos recursos orçamentários para criação de novas vagas no sistema prisional em unidades prisionais administradas por entidades civis, como é o caso da APAC. Essa conquista foi consequência do reconhecimento da capacidade dessa instituição em reabilitar os apenados (MINAS GERAIS, 2018).

\section{Categoria 4: vivências no cárcere}

Com base no posicionamento teórico adotado - ou seja, a compreensão de que o que é vivenciado no cárcere adquire tamanha intensidade que pode transformar a existência individual -, identificou-se a categoria "vivências" (BEZ BIROLO, 2010; VIESENTEINER, 2013). Desta ótica, foram enquadradas as situações vivenciadas no cotidiano das mulheres que englobam passagens de vários tipos de violência. Quando questionadas a respeito da adaptação à nova realidade, as entrevistadas foram unânimes quanto à dificuldade de ser mulher e estar presa, uma vez que possuem particularidades diferentes em relação aos homens. Para elas, a experiência no encarceramento é responsável por grandes transformações de natureza subjetiva em suas vidas. Constatou-se que, embora as situações experimentadas no cárcere sejam transformadoras tanto para homens quanto para mulheres, existem certas particularidades ligadas à identidade feminina. Considerando que 08 das 17 entrevistadas tiveram passagens pelo presídio regional, foi possível identificar nesta categoria vários tipos de violências vivenciados neste espaço.

Lá na masculina (presídio), eles têm mais privilégios... têm mais regalia. Eles recebem kit de higiene. A gente não recebe shampoo, absorvente, sabonete. A família que tem que comprar. Se não tem família, pede emprestado (E12).

As condições das mulheres são piores, tem mais desrespeito. Falta tratamento, valorização humana. Lá no presídio, a gente fazia as necessidades no chão, não tinha um banheiro. A mulher sofre mais, a diferença é muito grande, a gente é destruída moralmente, fica assustada (E1).

Lá (no presídio), a gente tomava banho, umas dez mulheres de uma vez. Dormia uma em cima da outra (E3).

A visita íntima também é um problema. É preciso ter união estável, precisa de testemunha. Eu tenho isso tudo e estão indeferindo (E9). 
É humilhação toda hora, a gente é chamada de vagabunda, piranha. Lá (no presídio) era pra entrar só agente feminina, mas os masculinos vão lá toda hora (E3).

Os homens têm muito mais privilégio. Até a estrutura é diferente. Eu falo que lá na masculina é o castelo e aqui é a senzala (E16).

O retorno das mulheres à sociedade estará carregado das experiências vividas por elas durante o período de execução da pena, e estas são entendidas de maneiras distintas por homens e mulheres. Nesta categoria torna-se essencial o papel do Estado, via políticas públicas, em contemplar as especificidades de gênero. $O$ desrespeito aos tratados internacionais e à legislação nacional, assim como citado por Almeida (2006), compromete o processo de retorno à sociedade, pois um sujeito que já não se reconhece e que vivenciou a perda de vínculos familiares e pessoais torna-se estigmatizado e sem perspectivas para dar prosseguimento à sua vida. As realidades vivenciadas por essas mulheres demarcam a prisão como um espaço legítimo, onde se trava um desafio das sequelas de um espaço gerador de identidades estigmatizadas (SOUZA, COSTA e LOPES, 2019).

\section{CONSIDERAÇÕES FINAIS}

Neste artigo buscou-se analisar em que medida a diferença de gênero na construção de políticas públicas de segurança influencia as vivências do feminino no cárcere. Por meio das informações coletadas, foram identificadas quatro grandes categorias, dentre as quais o constructo da categoria vivências constituiu ponto crucial deste trabalho, evidenciando as experiências que geram sua invisibilidade e transformação. A violência contra a mulher foi encarada como um comportamento natural e enraizado; longe de sofrer sanções estatais, as violências que se reproduzem nas relações no cárcere marcam definitivamente suas vidas (VIESENTEINER, 2013; MOTTA, 2017).

A categoria denominada maternidade perpassa também pelas vivências, visto se tratar da maior dificuldade apresentada pelas encarceradas que são mães. Empiricamente constatou-se a necessidade de falarem sobre o assunto e a visível emoção ao se lembrarem dos filhos. A realidade da previsão legal que garante a prisão domiciliar para as encarceradas gestantes e mães com filhos de até 12 anos ainda se configura como um desafio para que sua aplicação seja um direito legitimado.

À luz do referencial teórico, analisou-se outra categoria que revelou o universo do sistema prisional feminino e das políticas públicas de segurança. Historicamente, a legislação penal não abordou a questão da mulher que cometia crimes, potencializando assim a invisibilidade da mulher infratora. Analisar políticas públicas relacionadas ao sistema prisional feminino, bem como a realidade vivenciada por estas mulheres evidencia a necessidade da atuação estatal sob uma nova ótica, que precisa avançar em relação à recente inserção da questão de gênero na formulação das políticas públicas. Existe um enorme desafio, o de transformar as regras de proteção aos direitos das mulheres encarceradas em prática dentro dos estabelecimentos prisionais. Há que se investigar a fundo as dimensões estruturais e conjunturais implicadas no atual cenário de criminalização e aprisionamento de mulheres (GERMANO, MONTEIRO e LIBERATO, 2018).

As categorias identificadas demonstram a necessidade de um ponto de inflexão na tratativa do cárcere feminino pelo recorte de gênero. A desconsideração das peculiaridades deste universo reafirma uma visão estigmatizada e ineficiente, que, em muitos casos, não assegura que as mulheres encarceradas cumpram suas penas tendo todos seus direitos fundamentais assegurados. Os gestores do sistema carcerário entrevistados argumentaram que é difícil "lidar com as mulheres" e que estas apresentam muitos problemas relacionados à convivência. Nesse aspecto, muitas ações institucionais são voltadas a evitar e reprimir um comportamento atribuído exclusivamente ao gênero feminino.

Não se pretende aqui encontrar soluções definitivas para os problemas existentes no sistema carcerário feminino, mas avançar no debate. $O$ contexto que envolve a temática carece de ser abordado histórica e criticamente por meio de mais imersões empíricas. Dentre as limitações que este estudo teve, destaca-se o impedimento de entrevistar diretamente as detentas que se encontram no presídio regional. As análises deste espaço foram possíveis pelo significativo número de entrevistadas que já tiveram parte de suas penas cumpridas ali. A ampliação deste campo de investigação deve perpassar por diversas denominações e rearranjos. Assim, a reflexão final pauta-se exatamente dentro desta desconstrução de uma identidade única. Se o universo carcerário feminino foi identificado como um espaço que gera a invisibilização da mulher, qual seria a realidade das novas identidades construídas em meio a uma gama de novas identidade e subjetividades sociais? 


\section{REFERÊNCIAS}

ADORNO, S. Crime e violência na sociedade brasileira contemporânea. Jornal de Psicologia-PSI, n. 132, abr./jun., p. 7-8, 2002.

ALMEIDA, J. L. Os limites e as potencialidades de uma ação profissional emancipatória no sistema prisional brasileiro. 2006. 138f. Dissertação (Mestrado em Serviço Social) - Universidade Federal de Santa Catarina, Florianópolis, 2006.

ALMEIDA, L.; GOMES, R. C. Processo das políticas públicas: revisão de literatura, reflexões teóricas e apontamentos para futuras pesquisas. Cadernos EBAPE.BR, v. 16, n.3, p. 444-455, 2018.

ANDRADE, B. S. A. B. Entre as leis da Ciência, do Estado e de Deus: O surgimento dos presídios no Brasil. 2011. 317 f. Dissertação (Mestrado em Antropologia Social) - Universidade de São Paulo, São Paulo, 2011.

ARTUR, A. T. "Presídio de Mulheres": as origens e os primeiros anos de estabelecimento. São Paulo, 1930-1950. In: SIMPÓSIO NACIONAL DE HISTÓRIA, 25., Fortaleza, 2009. Anais... Fortaleza: ANPUH, 2009. Disponível em: <https://anpuh.org.br/uploads/anais-simposios/ pdf/2019-01/1548772192_1635d32f7239cd3bcf643523baabdd02. pdf>. Acesso em: 17 out. 2019.

BARDIN, L. Análise de Conteúdo. 4 ed. Lisboa: Edições 70, 2009.

BARDIN, L. Análise de Conteúdo. São Paulo: Edições 70, 2016.

BEAUVOIR, S. O segundo sexo. 3.ed. Rio de Janeiro: Nova Fronteira, 1980.

BEZ BIROLO, I. V. Puerpério em ambiente prisional: vivência de mulheres. 2010. 125f. Dissertação (Mestrado) - Universidade Federal de Santa Catarina, Centro de Ciências da Saúde, Programa de Pós-Graduação em Enfermagem, Florianópolis, 2010.

BORGES, Paulo César Corrêa. Direito penal democrático. São Paulo: Lemos e Cruz, 2005.

BOURDIEU, P. A dominação masculina. 11. ed. Rio de Janeiro: Bertand Brasil, 2012.

BRASIL. Constituição (1988). Constituição da República Federativa do Brasil: promulgada em 5 de outubro de 1988. 4. ed. São Paulo: Saraiva, 1990.

BRASIL. Ministério Público do Distrito Federal e Territórios. Plano Nacional de Segurança Pública. Brasília, DF: Governo Federal, 2000. Disponível em: <http://www.mpdft.mp.br/portal/pdf/unidades/ procuradoria_geral/nicceap/legis_armas/Legislacao_completa/

Plano_Nacional_de_Seguranca_Publica_2000_2002.pdf $>$. Acesso em: $1 \overline{8}$ out. 2019.

BRASIL. Presidência da República. Plano Nacional de Políticas para as Mulheres. Brasília, DF: Secretaria Especial de Políticas para as Mulheres, 2013.

BRASIL. Departamento Penitenciário Nacional. Levantamento Nacional de Informações Penitenciárias - Infopen Mulheres, 2. ed. Brasília, DF: Ministério da Justiça e da Segurança Pública, 2017a. Disponível em: <http://depen.gov.br/DEPEN/depen/sisdepen/infopen-mulheres/ infopenmulheres_arte_07-03-18.pdf>. Acesso em: 18 out. 2019.

BRASIL. Política Nacional de Segurança Pública e Defesa Social. Plano Nacional de Segurança Pública e Defesa Social 2018-2028. Brasília, DF: Ministério da Justiça e Segurança Pública, 2017b.
BRASIL. Decreto no 9.450, de $\mathbf{2 4}$ de julho de 2018. Dispõe sobre o procedimento de contratação de mão de obra formada por pessoas presas ou egressas do sistema prisional. Portaria Interministerial № 3, de 11 de setembro de 2018.

BRASIL. Lei no 13.257, de 08 de março de 2016. 2016. Disponível em: <http://www.planalto.gov.br/CCIVil_03/_Ato2015-2018/2016/ Lei/L13257.htm> Acesso em: 04 abr. 2018.

BREUS, T. L. Políticas Públicas no Estado Constitucional: a problemática da concretização dos direitos fundamentais sociais pela Administração Pública Brasileira Contemporânea. 2006. 244 f. Dissertação (Mestrado em Direito do Estado) - Universidade Federal do Paraná, Curitiba, 2006.

CARVALHO, V. A.; SILVA, M. R. F. Política de segurança pública no Brasil: avanços, limites e desafios. Revista Katálysis v. 14, n. 1, p. 59-67, jan./jun. 2011.

CHESKYS, D. Mulheres invisíveis: uma análise da influência dos estereótipos de gênero na vida de mulheres encarceradas. 2014. 134 f. Dissertação (Mestrado em Direito) - Pontifícia Universidade Católica do Rio de Janeiro, Rio de Janeiro, 2014.

CONSELHO NACIONAL DE JUSTIÇA - CNJ. Brasil tem 622 grávidas ou lactantes em presídios. 2018. Disponível em: http://www.cnj. jus.br/noticias/cnj/86062-brasil-tem-622-gravidas-ou-lactantes-empresidios. Acesso em: 18 out 2018.

CORTES, S. M. V.; LIMA, L. L. A contribuição da sociologia para a análise de políticas públicas. Lua Nova, v. 87, p. 33-62, 2012.

FARAH, M. F. S. Gênero e políticas públicas. Estudos feministas, v. 12, n. 1, p. 47-71, jan./abr. 2004.

FARAH, M. F. S. et al. Gênero e política pública: panorama da produção acadêmica no Brasil (1983-2015). Cadernos EBAPE.BR, v. 16, n. 3, p. 428-443, 2018.

FILOCRE, D’Aquino. Classificações de políticas de segurança pública. Revista Brasileira de Segurança Pública, ano 3, ed. 5, p. 146-158, ago./set. 2009.

FONSECA, F. A trama conflituosa das políticas públicas: Lógicas e projetos em disputa. Cadernos EBAPE.BR, v. 14, n. esp., p. 406417, 2016.

FÓRUM BRASILEIRO DE SEGURANÇA PÚBLICA - FBSP. Anuário Brasileiro de Segurança Pública. 11. ed. São Paulo: Fórum Brasileiro de Segurança Pública, 2018.

FRANÇA, M. H. O. Criminalidade e prisão feminina: uma análise da questão de gênero. Revista Ártemis, v. 18, n. 1, p. 212-227, 2014.

FREIRE, M. D. Paradigmas de segurança no Brasil: da ditadura aos nossos dias. Aurora, ano 3, n. 5, p. 49-58, 2009.

GERMANO, I. M. P.; MONTEIRO, R. A. F. G.; LIBERATO, M.T. C. Criminologia Crítica, Feminismo e Interseccionalidade na Abordagem do Aumento do Encarceramento Feminino. Psicologia: Ciência e Profissão, Brasília, v. 38, n. esp., p. 27-43, 2018. Disponível em <http://www.scielo.br/scielo.php?script=sci_arttext\&pid=S141498932018000600027\&lng=pt\&nrm=iso >. Acesso em: 18 out. 2019. http://dx.doi.org/10.1590/1982-3703000212310. 
GUEDES, M. A. Intervenções psicossociais no sistema carcerário feminino. Revista Psicologia: Ciência e Profissão, v. 26, n. 4, p. 558-569, 2006.

INSTITUTO DE PESQUISA ECONÔMICA APLICADA - IPEA; FÓRUM BRASILEIRO DE SEGURANÇA PÚBLICA - FBSP. Atlas da Violência 2018. 2018. Disponível em: <http://www.ipea.gov.br/portal/index. php?option=com_content $\&$ view $=$ article $\& i d=33410 \&$ Itemid $=432>$. Acesso em: 20 maio 2018.

LIMA, G. M. R. Continuidade de políticas públicas: a constitucionalização importa? 2011. 73 f. Dissertação (Mestrado em Administração Pública e Governo) - Fundação Getúlio Vargas, São Paulo, 2011.

LIMA, R. S.; BUENO, S.; MINGARDI, G. Estados, polícia e segurança pública no Brasil. Revista Direito GV, São Paulo, v. 12, n.1, p. 49-85, jan./abr. 2016.

MATOS, M. Teorias de gênero ou teorias e gênero? Se e como os estudos de gênero e feministas se transformaram em um campo novo para as ciências. Estudos Feministas, v. 16, n. 2, p. 333-357, 2008.

MINAS GERAIS. Tribunal de Justiça do Estado de Minas Gerais. 2018. Disponível em:<http://www.tjmg.jus.br/portal-tjmg/noticias/ apac-feminina-de-sao-joao-del-rei-e-inaugurada-oficialmente.htm\#. XbMM4-hKiUk>. Acesso em: 11 dez. 2018.

MINAYO, M. C. S. (Org.) Pesquisa social: teoria, método e criatividade. 21. ed. Petrópolis: Vozes, 2009.

MOTTA, M. C. C. Invisibilidades e persistências: políticas públicas de combate à Violência contra as Mulheres (Brasil e Argentina). 2017. 327f. Tese (Doutorado em Ciências Sociais) - Universidade de Brasília, Brasília, DF, 2017.

MUXÍ, Z. Mujeres en arquitectura y urbanismo. Summa+, Buenos Aires, n. 136, p. 144-147, jun., 2014.

NASCIMENTO, J. X. Políticas Públicas e Desigualdade de Gênero na Sociedade Brasileira: Considerações Sobre os Campos do Trabalho, da Política e da Ciência. Mediações, v. 21, n. 1, p. 317-337, jul./dez. 2016.

POSADA, R. A. U. Questões associadas ao encarceramento parental: uma análise das características da população de pais e mães encarcerados e da situação de seus filhos em Minas Gerais, 2014. 2015. 177 f. Dissertação (Mestrado em Demografia) - Universidade Federal de Minas Gerais, Belo Horizonte, 2015.

RAMPIN, T. T. D. Mulher e sistema penitenciário: a institucionalização da violência de gênero. In: BORGES, P. C. C. (Org.). Sistema Penal e Gênero: tópicos para a emancipação feminina. São Paulo: Cultura Acadêmica, 2011

SANTA RITA, R. P. Mães e crianças atrás das grades: em questão o princípio da dignidade da pessoa humana. 2006. 180 f. Dissertação (Mestrado em Política Social) - Universidade de Brasília, 2006.

SARAVIA, E. Introdução à teoria da política pública. In: SARAVIA, E.; FERRAREZI, E. (Org.). Políticas públicas. Brasília, DF: ENAP, 2006. v. 1. p. 21-42.
SCAVONE, L. Gênero, feminismo e políticas sociais. In: SOUZA, L. A. F; MAGALHÃES, B. R.; SABATINE, T. T. (Org.). Desafios à Segurança Pública: controle social, democracia e gênero. São Paulo: Cultura Acadêmica, 2012. 228p.

SCHABBACH, L. M. A agenda da segurança pública no Brasil e suas (novas) políticas. In: MADEIRA, L. M. (Org.). Avaliação de Políticas Públicas. Porto Alegre: UFRGS, 2014. 254p.

SILVA, J. A. Comentário contextual à Constituição. São Paulo: Malheiros, 2009.

SILVEIRA, M. L. Políticas públicas de gênero: impasses e desafios para fortalecer a agenda política na perspectiva da igualdade. In: GODINHO, T.; SILVEIRA, M. L. (Org.). Políticas públicas e igualdade de gênero. São Paulo: Coordenadoria Especial da Mulher, 2004.

SOARES, V. Políticas públicas para igualdade: papel do Estado e diretrizes. In: GODINHO, T.; SILVEIRA, M. L. (Org.). Políticas públicas e igualdade de gênero. São Paulo: Coordenadoria Especial da Mulher, 2004

SORJ, B. A Revista Estudos Feministas e as políticas públicas: qual relação? Estudos Feministas, v. 16, n. 1, p. 129-130, 2008.

SOUZA, C. Políticas públicas: questões temáticas e de pesquisa. Caderno CRH, n. 39, p. 11-24, jul./dez. Salvador, 2003.

SOUZA, C. Políticas Públicas: uma revisão da literatura. Sociologias, Porto Alegre, v. 8, n. 16, p. 20-45, jul./dez. 2006.

SOUZA, E. M.; COSTA, A. M.; LOPES, B. C. Ressocialização, trabalho e resistência: mulheres encarceradas e a produção do sujeito delinquente. Cadernos EBAPE.BR, v. 17, n. 2, p. 362-374, 2019.

SOUZA, L. A. F. et al. Políticas locais de segurança pública. In: SOUZA, L.A.F. (Org.). Políticas Públicas de Segurança no Estado de São Paulo: situações e perspectivas a partir das pesquisas do Observatório de Segurança Pública da UNESP. São Paulo: Editora UNESP, 2009. 219p.

UZIEL. A. P. SCISLESKI, A. C. C. Sistema Prisional e Segurança Pública: Inquietações e Contribuições da/à Psicologia. Psicologia: Ciência e Profissão v. 38, n. esp., p. 3-9, 2018.

VASONE, N. B.; SANTANA, I. J. Mulheres e Prisão; Gestação e Liberdade. In: SCIENCULT, 11., Parnaíba, 2015. Cadernos de programação e resumos. Organização: Maria Silvia Rosa Santana. Paranaíba, MS: UEMS, 2015. v. 11.

VIESENTEINER, J. L. O conceito de vivência (Erlebnis) em Nietzsche: Gênese, significado e recepção. Kriterion, Belo Horizonte, n. 127, p. 141-155, jun. 2013.

ZACCHI, J. M. Prevenção da violência: avanços e desafios na ordem do dia. In: ILANUD. Das Políticas de Segurança Pública às Políticas Públicas de Segurança. São Paulo: ILANUD, 2002. p. 31-42. 
Bruna Rios Martins Santos

\section{ORCID: https://orcid.org/0000-0002-3987-3613}

Mestre em Administração Pública pela Universidade Federal de São João del-Rei (UFSJ); Enfermeira na Universidade Federal de São João del-Rei (UFSJ), São João del-Rei-MG, Brasil. E-mail: brunariosm@ufsj.edu.br

\section{Vânia Aparecida Rezende} ORCID: https://orcid.org/0000-0002-9879-4552

Doutora em Administração pelo Programa de Pós-Graduação em Administração da Universidade Federal de Lavras (UFLA); Professora adjunta na Universidade Federal de São João del-Rei (UFSJ), São João del-Rei, MG, Brasil. E-mail: vaniarezende@ufsj.edu.br 